Research Article

\title{
Optimal Analysis of Tunnel Construction Methods through Cross Passage from Subway Shaft
}

\author{
Zhanping Song, ${ }^{1,2}$ Zhilin Cao $\mathbb{D}^{1},{ }^{1}$ Junbao Wang $\mathbb{D},{ }^{1}$ Shoufeng Wei, ${ }^{2}$ Shichun $\mathrm{Hu}\left(\mathbb{D},{ }^{2}\right.$ \\ and Zelin Niu ${ }^{1,2}$ \\ ${ }^{1}$ School of Civil Engineering, Xi'an University of Architecture and Technology, Xi'an 710055, China \\ ${ }^{2}$ Chinese Railway Bridge Engineering Bureau Group Co. Ltd., Tianjin 300300, China \\ Correspondence should be addressed to Junbao Wang; xajdwangjunbao@163.com
}

Received 18 August 2017; Accepted 27 December 2017; Published 28 February 2018

Academic Editor: Giovanni Garcea

Copyright (c) 2018 Zhanping Song et al. This is an open access article distributed under the Creative Commons Attribution License, which permits unrestricted use, distribution, and reproduction in any medium, provided the original work is properly cited.

\begin{abstract}
The conversion section of the cross passage and shaft is a priority concern in the stress transformation of a tunnel structure during subway underground excavation. In the construction of Subway Line 5 in Xi'an, China, the main line in the loess layer was constructed through the cross passage from the subway shaft of the Yue Deng Pavilion-San Dian Village Station tunnel section. Numerical simulation and field measurement were adopted to study the construction stability of the cross passage and shaft under two possible construction methods: the "shaft followed by cross passage construction" method and the "cross passage parallel shaft construction" method. The results showed that the surface deformation and plastic zone of the surrounding rock are similar under the two construction methods. However, of the two, the "cross passage parallel shaft construction" method was more advantageous in controlling the structural deformation of the original shaft and the stress distribution of the horsehead structure. The field monitoring data showed that the surface settlements and the deformation of the original shaft structures meet the requirement of control standards under the "cross passage parallel shaft construction" method.
\end{abstract}

\section{Introduction}

To reduce the impact of subway construction on ground transportation, especially in the busiest areas of urban cities, subway engineering is often accomplished using the mining method or covered excavation method [1-8]. The station or tunnel section is often constructed through the shaft from the cross passage under the mining method. The stress states and displacements around the conversion section between the shaft and cross passage are three-dimensional [9-11]. The surrounding rock masses in the conversion areas are more heavily disturbed than in common tunnels [12-14].

Therefore, keeping the construction of the subway shaft and cross passage safe, especially the horsehead between the shaft and cross passage, is the key and the basis to successful underground construction. There are two commonly used construction methods through a cross passage from a subway shaft. The first method is the "shaft followed by cross passage construction" method, in which the construction sequence is first to excavate the shaft to the design elevation and then excavate the cross passage through the temporary construction platform above the shaft nest. The second method is the "cross passage parallel shaft construction" method, in which the construction sequence is first to excavate the shaft to the temporary inverted arch elevation of the top heading of the cross passage, next to excavate the top heading of the cross passage to the design footage, and then excavate the remaining part of shaft and cross passage.

Wang and Zhang [15] analyzed the process characteristics of these two construction methods for construction of the shaft crossing passage at the tunnel section between Zhanglu Station and Shen Xin Road Station, Shenyang 
Subway Line 1, China. They proposed that the "cross passage parallel shaft construction" method was better adapted to the good geological condition under the shaft bottom and discussed the superiority of the method. In view of the stability of the shaft and cross passage, He et al. [16] analyzed the shaft and horsehead stress characteristics at different shaft sections and proposed different auxiliary methods of constructing the horsehead and shaft at different shaft sections when using the "shaft followed by cross passage construction" method. For the construction of the Metro Line 5/6 transfer station in Guangzhou, China, Bai and Ji [17] analyzed the stability of the pile-beam system that was used in the construction of the shaft and cross passage and put forward construction response measures, effectively for controlling the settlement of the ground surface. Regarding the construction of the tunnel section between the Yijing Road and Huang Bei Ling station of the Metro Line 5 in Shenzhen, China, Jiang et al. [18] discussed the reinforcement measures for controlling the settlement during construction of the shaft and cross passage. To control the horizontal convergence deformation during the crossing passage construction procedure and ensure the stability of the construction, they proposed the rapid closure measures during horsehead construction.

The aforementioned research on specific engineering techniques has positive guiding significance for controlling deformation and safety of subway shaft crossing passage construction. However, there has been little research on the determination of tunnel construction methods through the cross passage from a subway shaft, or on the influence that different construction methods make to the deformation of the ground surface and shaft-cross passage structure. In practice, the shaft structure is under homogeneous soil pressure before the horsehead is excavated. After excavation of the horsehead, because of the free face of the shaft structure near the horsehead, the shaft is in a biased state, and the stratum's bias pressure is balanced by the friction from the earth pressure on both sides of the horsehead and by the combined effect of the horsehead support force and soil arching. If the force state does not reach equilibrium, the construction may produce a collapse. The different intersection construction methods between a shaft and cross passage create different force states in the horsehead section. To assure a safe balanced state of the horsehead section, optimal analysis of the different construction methods of the horsehead section is necessary.

In this study, we examined the construction of Subway Line 5 in Xi'an, China; the main line loess tunnel of which was constructed through the cross passage from the subway shaft at the Yue Deng Pavilion-San Dian Village Station tunnel section. Numerical simulation and field measurement were adopted to study the ground surface deformation and the deformation and stress distributions of the original shaft structure, as well as the plastic zone of the surrounding rock characteristics under two construction techniques: the "shaft followed by cross passage construction" method and the "cross passage parallel shaft construction" method. The results were intended to provide a theoretical basis and technical support for the design and construction of shaft and cross passages in loess areas.

\section{Project Description}

Subway Line 5 is a very important traffic thoroughfare from east to west in the Xi' an subway network. The line has a total length of $45.37 \mathrm{~km}$ and a total of 34 sites, and the whole line is divided into two projects. The length of the first project is $25.24 \mathrm{~km}$, traversing west to the Peace Industrial Park and east to the Textile City Railway Station. The tunnel section between Yue Deng Station and San Dian Village Station in the first project was designed to be constructed using the mining method. At location ZDK44+310, the main regional tunnel was excavated through the service gallery, a shaft, and a cross passage. The relative positions of the subway and the construction shaft are shown in Figure 1.

The engineering site was in the third grade terrace of Xi'an, along the Chan River, and the site terrain was flat. The elevation of the exploration site varied from $450.67 \mathrm{~m}$ to $455.4 \mathrm{~m}$ (Figure 2). There were no important buildings around the site, and the area is consisted of planning plots and wasteland. The depth of the groundwater was 30.00$39.35 \mathrm{~m}$ (elevation $414.48-421.00 \mathrm{~m}$ ). The annual variation of the water level was $2.0-3.0 \mathrm{~m}$. The underground structure of the tunnel section was above the groundwater level, so the impact of the groundwater could be ignored.

The horizontal dimension of the shaft was $5.0 \mathrm{~m} \times 6.5 \mathrm{~m}$. The depth of the shaft was $22.451 \mathrm{~m}$. The cross passage had a total length of $27.932 \mathrm{~m}$, a net width of $4.5 \mathrm{~m}$, and a net height of $7.35 \mathrm{~m}$. The cross passage was equipped with a horsehead. A shaft wellhead set up the locking ring beam, and the size of the ring beam section was $2 \mathrm{~m} \times 1 \mathrm{~m}$. Shaft support parameters are shown in Table 1, and the cross passage support parameters are shown in Table 2.

\section{Numerical Model}

The intersection construction between the shaft and cross passage was described in a numerical model. Two different construction methods (Section 3.1) were examined. The model was established using MIDAS GTS finite element software (http://en.midasuser.com/) to analyze the resulting surface subsidence, the plastic zone of the surrounding rock, and the stress and displacement distribution of the original shaft structure. The model also was used to identify the optimal construction method and construction priorities.

3.1. Construction Procedures. The two construction methods for the tunnel section between Yue Deng Station and San Dian Village Station were the "shaft followed by cross passage construction" method (hereinafter referred to as Method 1) and the "cross passage parallel shaft construction" method (hereinafter referred to as Method 2).

In both methods, the intersection construction between the shaft and crossing passage was divided into three phases: locking section construction, shaft well construction, and top heading and bench of the horsehead construction. According to the design layout, a draining well was to be arranged to advance the site drainage before excavating the shaft so that the construction of the shaft and cross passage 


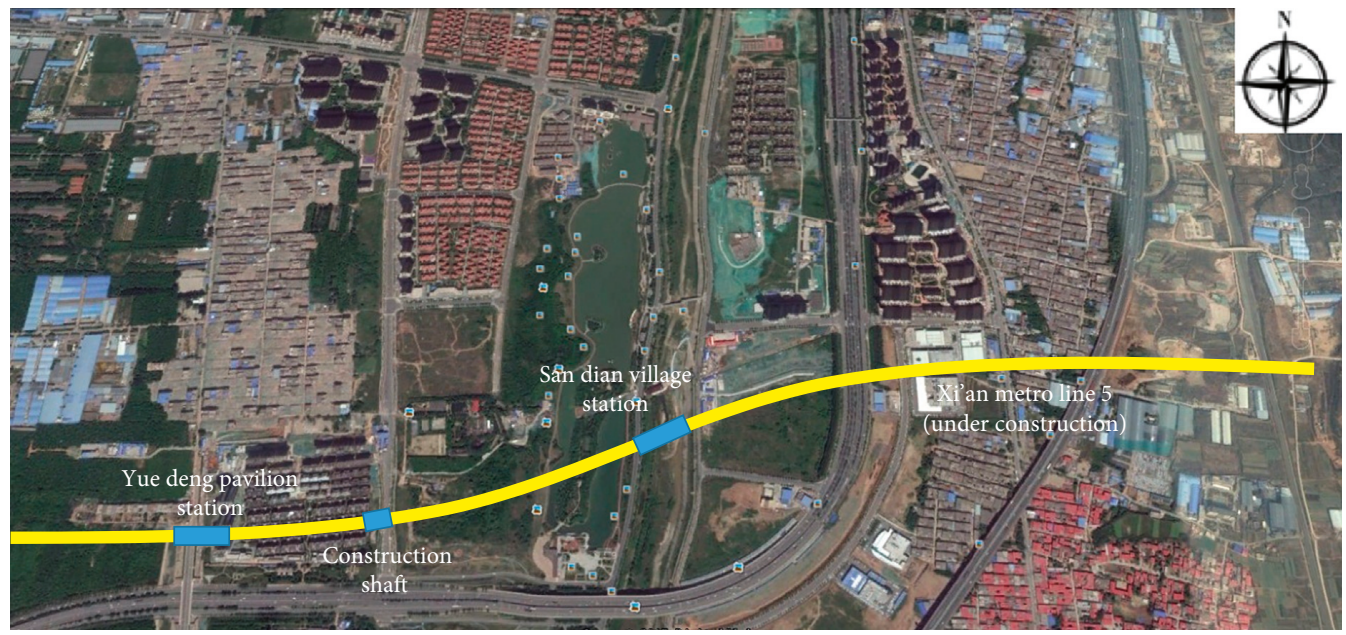

Figure 1: Study area.

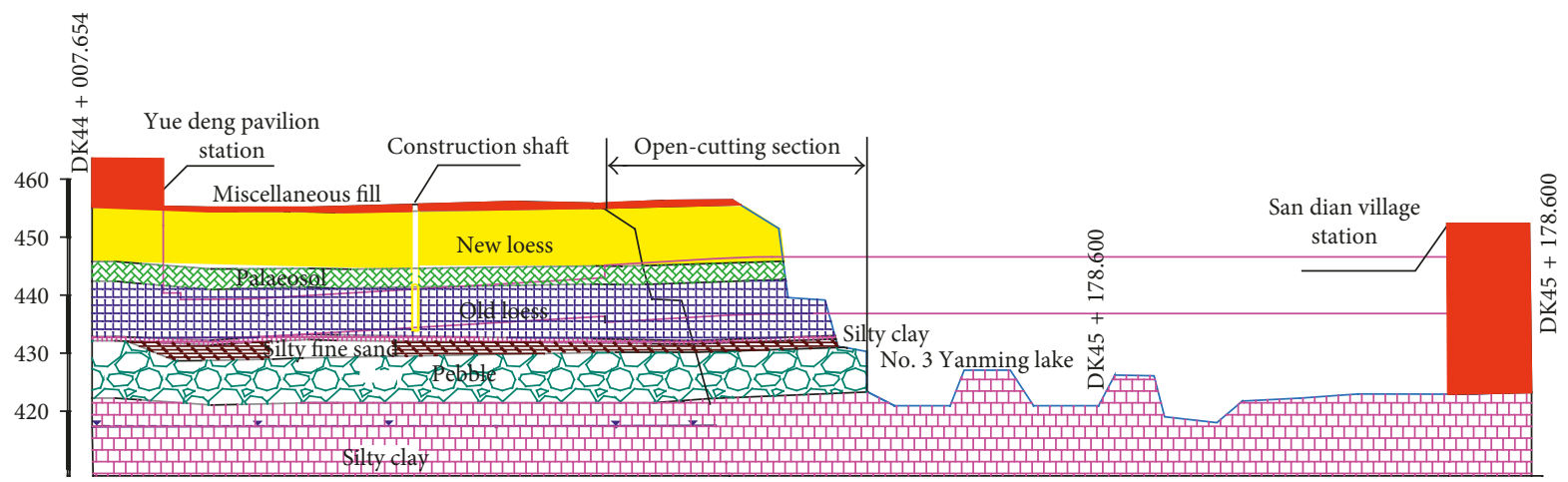

FIgURe 2: Profile of soil layers, tunnel from Yue Deng Pavilion Station to San Dian Village Station (units: m; vertical scale: 1 : 100; horizontal scale: $1: 1,000)$.

TABLE 1: Shaft support parameters.

\begin{tabular}{lccc}
\hline Item & & Main materials and specifications & Structure size \\
\hline & Leading conduit & $\Phi 42 * 3.5$, length $=2 \mathrm{~m}$ and $3.5 \mathrm{~m}$, steel flower tube & Spacing: $1.0 * 1.0 \mathrm{~m}$ and $1.5 * 1.5 \mathrm{~m}$ \\
Gupport & Grid steel frame & C25, C14 steel & Vertical clearance: 0.75 and $0.5 \mathrm{~m}$ \\
& Mesh reinforcement & $\Phi 8150 * 150 \mathrm{~m}$ grid & Surrounded by laying, double \\
& Vertical reinforcement & C22 steel bar & Ring spacing: $1.0 \mathrm{~m}$, double \\
& Shotcrete & C25 early strength concrete & Thickness: $0.4 \mathrm{~m}$ \\
\hline
\end{tabular}

TABLE 2: Cross passage support parameters.

\begin{tabular}{lccc}
\hline Item & & Main materials and specifications & Structure size \\
\hline & Big pipe shed & $\Phi 108 * 6$ & Length: $10 \mathrm{~m}$; ring spacing: $0.5 \mathrm{~m}$ \\
Ring spacing $0.3 \mathrm{~m}$ & Vertical clearance: $1.5 \mathrm{~m}$ \\
Leading conduit & $\Phi 42 * 3.5$, length $=2 \mathrm{~m}$ and $3.5 \mathrm{~m}$, steel bar & Vertical clearance: $0.5 \mathrm{~m}$ \\
Support & Grid steel frame & C25, C14 steel bar & Surrounded by laying, double \\
& Mesh reinforcement & $\Phi 8150 * 150 \mathrm{~m}$ grid & Ring spacing: $1.0 \mathrm{~m}$, double \\
& Vertical reinforcement & C22 steel bar & Thickness: $0.3 \mathrm{~m}$ \\
& Shotcrete & C25 early strength concrete & Thickness: $0.6 \mathrm{~m}$ \\
\hline
\end{tabular}


could be accomplished in dry soil. The construction sequence of Method 2 is shown in Figure 3. However, if steps 3 and 4 in the construction sequence illustrated by Figure 3 were exchanged, the diagram would describe the construction sequence of Method 1. Thus, the main difference between the two construction methods was the excavation sequence of the top heading of the horsehead. In Method 1, the excavation procedure of the horsehead occurred after the part of the shaft below the top heading level was excavated, but in Method 2, the horsehead excavation was completed before the part of the shaft below the top heading level was excavated. The two methods caused different stress and deformation distributions in the surrounding rock and had different spatial effects on the construction safety status.

3.2. Geological Model and Boundary Conditions. In the numerical analysis, the $x$-axis negative direction was defined as the cross passage tunneling direction, and the $z$-axis was positive upwards. A three-dimensional numerical model of the shaft and cross passage was built to analyze the influence of construction. A perspective view of the numerical model is shown in Figure 4. According to the site geological conditions, the stratum was simplified to a homogeneous horizontally layered distribution. Taking into account the size of the finite element model supported by the computer hardware and in order to save the calculation time of numerical simulation, the sizes of the bottom and side boundaries are both set to about $16 \mathrm{~m}$. The distances between the side of the shaft and the boundary of the numerical model are determined as $15 \mathrm{~m}$ (3 times of the width of the shaft), and the distance between the bottom of the cross passage and the boundary of the numerical model is determined as $17 \mathrm{~m}$ (2.5 times of the height of cross passage). The numerical analysis model simulated a space of $66 \mathrm{~m} \times 36 \mathrm{~m} \times 36 \mathrm{~m}$ in three directions $\mathrm{X}, \mathrm{Y}, \mathrm{Z}$, respectively. The rock mass was simulated using solid hexahedron elements. The thickness of the preliminary tunnel support was $250 \mathrm{~mm}$, the thickness of the temporary support was $100 \mathrm{~mm}$, and both supports were simulated using a shell element. Based on its actual size, the ring beam of the shaft was simulated using a solid element. In total, the finite element model consisted of 43,802 elements and 56,326 nodes. To simulate the boundary conditions, the nodes on all sides of the model were fixed in the horizontal directions on the $\mathrm{X}-\mathrm{Z}$ and $\mathrm{Y}-\mathrm{Z}$ planes, whereas the nodes at the base of the model were fixed in the vertical $(Z)$ direction and the surface of the model was free to move.

\subsection{Constitutive Model and Calculation Parameters. Based} on the geological survey report of the tunnel section between Yue Deng Station and San Dian Village Station, the surrounding rocks of the shaft and cross passage were mainly composed of miscellaneous fill, new loess, paleosol, and old loess (designated Q2eol). The physical and mechanical parameters are shown in Table 3.

The yield criterion commonly used in geotechnical engineering includes Tresca criterion, Mises criterion, DruklePlager criterion, and Mohr-Coulomb criterion, and so on.

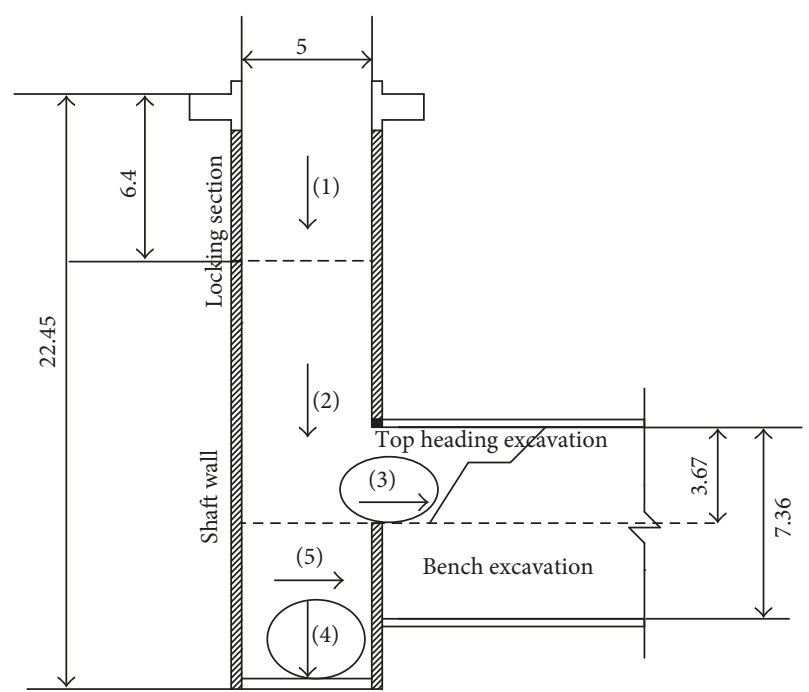

Figure 3: Construction sequence of Method 2 (unit: mm).

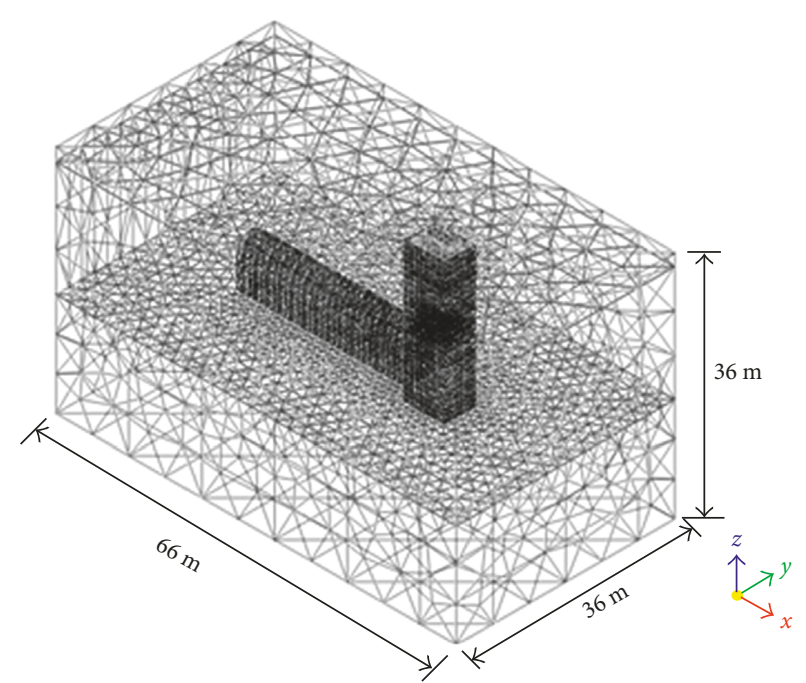

Figure 4: Finite element model of the shaft and cross passage.

Among them, the Mohr-Coulomb criterion can well reflect the strength effects of soils and the sensitivity to hydrostatic pressure and is simple and practical. The physical and mechanical parameters, cohesion $(c)$, and angle of internal friction $(\varphi)$ can be determined by different routine tests. Depending on a series of experiments, Chen et al. [19-21] pointed out that the Mohr-Coulomb criterion is able to describe the strength characteristics of loess, and this criterion can be used to guide and design the actual structural construction in the loess layer. Combining with the physical and mechanical parameters of the soils provided by the geological survey report of the tunnel section, the Mohr-Coulomb criterion was adopted to describe the behavior of surrounding loess layer.

Because the preliminary support and temporary support of the shaft and cross passage included steel arches, metal mesh, and shotcrete, the analysis included an equivalent model based on the parameters of a steel arch, metal mesh, 
TABle 3: Physical and mechanical parameters of model.

\begin{tabular}{|c|c|c|c|c|c|c|}
\hline Material & $\begin{array}{l}\text { Unit weight } \\
\left(\mathrm{kN} / \mathrm{m}^{3}\right)\end{array}$ & $\begin{array}{l}\text { Elastic modulus } \\
(\mathrm{MPa})\end{array}$ & $\begin{array}{l}\text { Poisson's } \\
\text { ratio }\end{array}$ & $\begin{array}{c}\text { Angle of internal friction } \\
\left({ }^{\circ}\right)\end{array}$ & $\begin{array}{l}\text { Cohesion } \\
(\mathrm{kPa})\end{array}$ & $\begin{array}{l}\text { Thickness } \\
\text { (m) }\end{array}$ \\
\hline Miscellaneous fill & 16.5 & 9.0 & 0.43 & 16.0 & 5.0 & 2.0 \\
\hline New loess & 15.8 & 13.5 & 0.375 & 21.0 & 25.0 & 11.0 \\
\hline Paleosol & 17.3 & 24.0 & 0.29 & 20.0 & 35.0 & 8.0 \\
\hline Old loess & 15.9 & 18.0 & 0.35 & 20.0 & 30.0 & 17.0 \\
\hline Ring beam & 25 & 30,000 & 0.2 & - & - & 1.0 \\
\hline Early support & 22.0 & 23,500 & 0.2 & - & - & 0.25 \\
\hline $\begin{array}{l}\text { Temporary } \\
\text { support }\end{array}$ & 22.0 & 17,500 & 0.2 & - & - & 0.1 \\
\hline
\end{tabular}

and shotcrete (Tables 1 and 2). The elastic modulus of the equivalent model was described as follows:

$$
E=E_{0}+\frac{S_{g} E_{g}}{S_{0}},
$$

where $E$ is the initial support elastic modulus after conversion, $E_{0}$ is the elastic modulus of sprayed concrete, $E_{g}$ is the elastic modulus of steel bars, $S_{q}$ is the cross section of steel, and $S_{0}$ is the cross section of concrete.

According to the analysis and calculation, the physical and mechanical parameters of the equivalent support are shown in Table 3. Support materials were treated as elastomers in the model.

3.4. Simulated Construction Procedure. The shaft and cross passage construction process was simulated using a step-bystep approach. A total of 90 steps were used in each of the two construction methods. The excavation was simulated by removing the elements in front of the tunnel face, and the supporting structure was simulated by activating the structural elements. The supporting structures were installed immediately after the excavation of the shaft and cross passage. The length of the excavation at each step in the construction was $1 \mathrm{~m}$. The two construction processes were as follows.

\section{Method 1}

(1) The shaft locking section was excavated using the full-face excavation method, and then the ring beam was set up. The total length of the step was $3 \mathrm{~m}$.

(2) The shaft well was excavated, and shaft supporting structure was constructed until the bottom of the shaft was reached; then the permanent closed bottom construction of the shaft was completed. The total length of the step was $18 \mathrm{~m}$.

(3) The top heading excavation of the cross passage was completed, and the supporting structure was constructed. The total length of the step was $6 \mathrm{~m}$.

(4) The bench excavation of the cross passage was completed, and the supporting structure was constructed. The total length of the step was $3 \mathrm{~m}$.

(5) The top heading and bench excavation of the cross passage were constructed to the designed length. The entire construction simulation was completed.
Steps 1-24 were used to simulate the construction of the shaft, steps 25-37 were implemented to model the construction of the horsehead, and steps 38-90 were used to simulate the construction of the cross passage.

\section{Method 2}

(1) The shaft locking section was excavated using the full-face excavation method, and then the ring beam was set up. The total length of the step was $3 \mathrm{~m}$.

(2) The shaft well was excavated, and the shaft supporting structure was constructed until the temporary inverted arch elevation position of top heading of the cross passage was reached; then the temporary closure of the bottom of the shaft was constructed at the design height of the top heading. The total length of the step was $14 \mathrm{~m}$.

(3) The top heading excavation of the cross passage was completed, and the supporting structure was constructed. The total length of the step was $6 \mathrm{~m}$.

(4) The temporary closure of the bottom of the shaft was dismantled. The remaining part of the shaft was constructed, and the permanent closing support of the shaft bottom was constructed. The total length of the step was $4 \mathrm{~m}$.

(5) The bench excavation of the cross passage was first excavated to $3 \mathrm{~m}$. Then the top heading and bench excavation of the cross passage were constructed to the design length. The entire construction simulation was completed.

Steps 1-20 and steps $28-33$ were used to simulate the construction of the shaft. Steps $21-27$ and steps 34-38 were implemented to model the construction of the horsehead, and steps 39-90 were used to simulate the construction of the cross passage.

\section{Numerical Simulation Results}

4.1. Comparative Analysis of Ground Settlement. When a subway is constructed through an environmentally sensitive area, the settlement deformation of the ground surface is an important index of construction safety [22,23]. Cloud diagrams of the ground settlement were used to portray the deformation predicted in the two numerical simulations. Figures 5(a) and 5(b) show the ground settlement resulting 


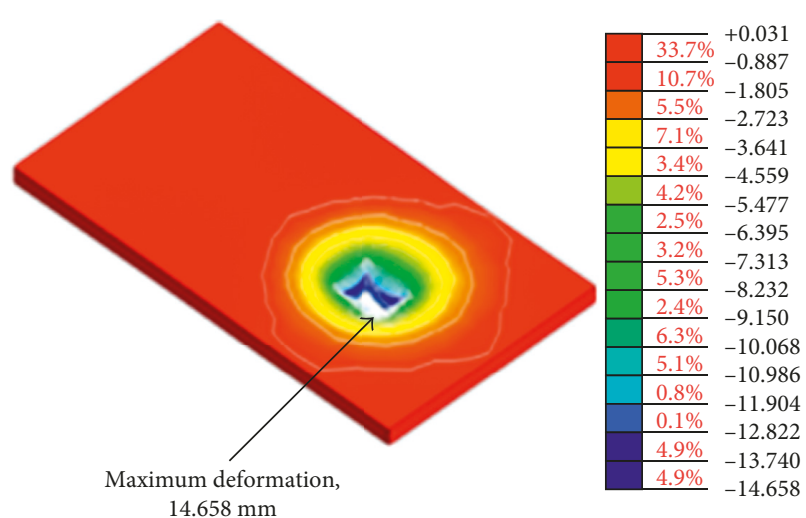

(a)

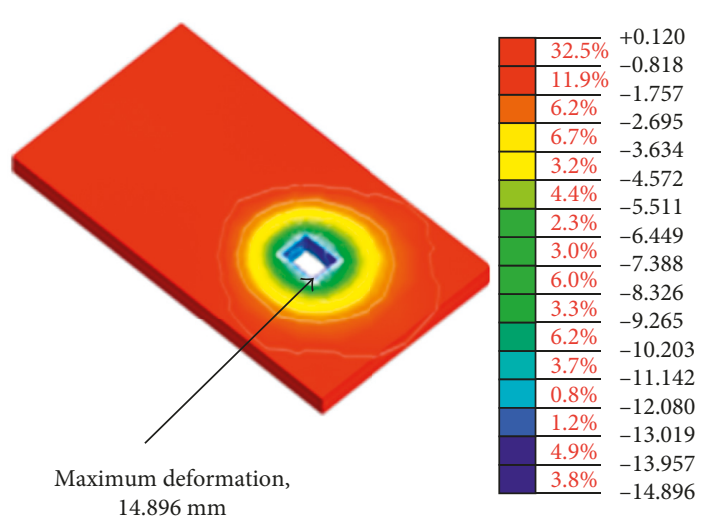

(b)

Figure 5: Ground surface settlement resulting from construction methods 1 and 2 (units: mm). (a) Method 1. (b) Method 2.

from construction Method 1 and Method 2, respectively. The predicted ground settlement caused by the two construction methods was very similar, and the pattern of surface deformations was similar to an ellipse with its long axis parallel to the direction of the cross passage. At the end of construction, the maximum ground settlement (approximately $15 \mathrm{~mm}$ ) appeared at the shaft ring beam in the direction away from the cross passage.

4.2. Comparative Analysis of the Plastic Zone. The plastic zone of the surrounding rock mass is an important index for the stability of the material surrounding the tunnel [24, 25]. The plastic distribution of the rock mass surrounding the shaft and cross passage was approximately the same at the end of construction regardless of the construction method used (Figure 6). The large range of the plastic distribution was concentrated in an area that was $0-3 \mathrm{~m}$ outside the vertical shaft wall at about the horsehead elevation and $0-1 \mathrm{~m}$ in the rock mass surrounding the shaft and invert of the cross passage.

To compare and analyze the most dangerous position of plastic deformation of surrounding rock resulting from the two construction methods, a plastic deformation value $\geq 100 \mu \varepsilon$ was selected (Figure 7 ). The maximum deformation of the plastic zone in the surrounding rock occurred at the invert of the horsehead when Method 1 was used and at the foot of the top heading of the horsehead when Method 2 was used. Thus, although the overall distribution of plastic deformation in the rock surrounding the shaft and cross passage was approximately the same in two construction methods, the locations of the maximum deformation were different. In actual construction, different construction methods need to strengthen different locations, especially the invert and the foot of the top heading of the horsehead. In addition, the weak rock surrounding the horsehead also needs to be strengthened to prevent the rock surrounding the invert and haunch from collapse.

4.3. Comparative Analysis of Shaft Support Stability. In the excavation process of the underground structure, the deformation and stress distribution of the supporting structure can directly reflect the stability of the surrounding rock. Furthermore, different construction programs can produce different changes in the shaft support structure.

According to the coordinate system shown in Figure 4, Table 4 shows that the position of the maximum deformation in the $\mathrm{X}, \mathrm{Y}$, and $\mathrm{Z}$ directions was the same under the two methods. The maximum deformation in the $\mathrm{X}$ and $\mathrm{Y}$ directions occurred in the cross section of the horsehead, and the maximum deformation in the $\mathrm{Z}$ direction occurred at the bottom of the shaft. However, the maximum deformation produced by construction Method 2 was $21.91 \%$, $9.26 \%$, and $0.52 \%$ less than that produced by Method 1 in the $\mathrm{X}, \mathrm{Y}$, and $\mathrm{Z}$ directions, respectively.

Figure 8 shows the horizontal displacement of the shaft wall at different depths at the end of construction. Figure 8(a) shows the change of the horizontal displacement of the shaft wall away from the cross passage in the four shaft walls at the different depths. Figure 8(b) shows the change of the horizontal displacement of the shaft wall parallel to the cross passage axis in the four shaft walls at the different depths.

As shown in Figure 8(a), all points in the shaft wall occurred convergence deformation as a result of both construction methods, and at depths of $0-10 \mathrm{~m}$, the horizontal deformations were the same. At depths of $10-21 \mathrm{~m}$, the horizontal deformations resulting from Method 2 were relatively larger than those resulting from Method 1 . The deformations that were most different from the two construction methods appeared within the height of the horsehead (depth $14-21 \mathrm{~m}$ ). At the depth of $18 \mathrm{~m}$ (which was the height of the haunch of the horsehead), the maximum difference in deformation of the shaft support was about $20 \%$ for the two methods. Below the depth of $21 \mathrm{~m}$, the deformation of the shaft under the two methods tended to be the same. Nevertheless, the shaft support deformations caused by the two construction methods were relatively small $(<10 \mathrm{~mm})$.

As shown in Figure $8(\mathrm{~b})$, the points of the shaft wall under the two construction methods also occurred convergence deformation, and at depths of $0-12 \mathrm{~m}$, the horizontal deformations were the same. At the depth of $4 \mathrm{~m}$, there was a bending point as the same as in Figure 8(a). 


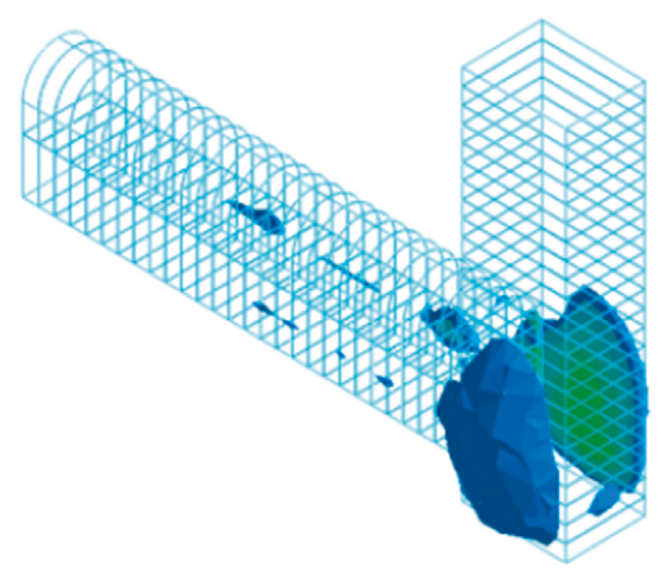

(a)

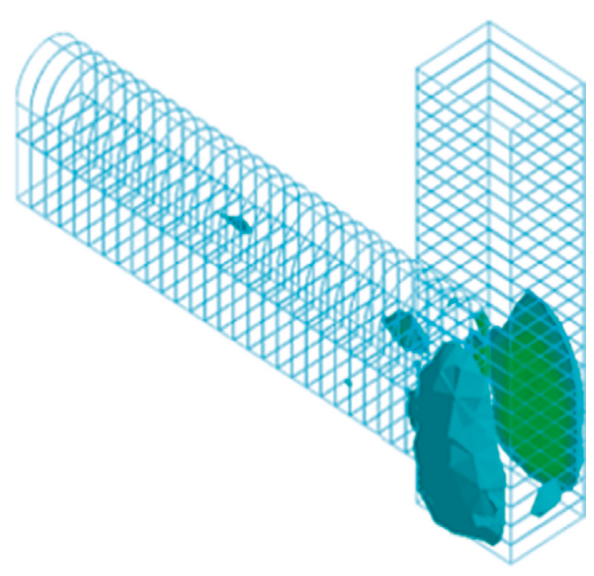

(b)

FIgURe 6: Plastic zone distribution in surrounding rock. (a) Method 1. (b) Method 2.

Because at the depths of $0-3 \mathrm{~m}$, the shaft wall was constructed with the ring beam, and the ring beam restrained the deformation of the four shaft walls. Within the height of the horsehead (depth of $12-21 \mathrm{~m}$ ), the deformation of the shaft wall under Method 2 was smaller than Method 1. The largest difference $(2.36 \mathrm{~mm}$ or $9.26 \%$ ) between deformations resulting from the two methods occurred at the depth of $18 \mathrm{~m}$, which was the same as the depth where the maximum deformation appeared. The maximum deformations under Method 1 and Method 2 at the depth of $18 \mathrm{~m}$ were $24.09 \mathrm{~mm}$ and $21.73 \mathrm{~mm}$, which were very close to the safety limit. This illustrated that Method 2 was more conducive to control the maximum deformation than Method 1. Even under Method 2 , the haunch of the horsehead (the depth of $18 \mathrm{~m}$ ) was also the dangerous location, which was needed to be strengthened support. Below the depth of $21 \mathrm{~m}$, the deformation of the shaft under the two methods tended to be the same.

The maximum stresses of the shaft support after construction under the two construction methods are given in Table 5. The maximum principal stress and ultimate shear stress of the structure support were $14.38 \%$ and $19.57 \%$ lower, respectively, for Method 2 than for Method 1, which greatly improved the support force. Under both construction methods, the maximum principal stress and ultimate shear stress occurred in the vertical shaft wall near the horsehead arch. In practice, either construction method would need to focus on this location to assure safety.

4.4. Comparative Analysis of Horsehead Supporting Stability. To compare the influence of the two construction methods on the intersection between the shaft and cross passage in the horsehead section (Figure 9), the horizontal displacement of the shaft support in the Y direction at the height of the temporary closure face was selected to dynamically analyze the displacement changes following each simulated construction step. Because at construction step 19, this position of this shaft support was reached, and at construction step 56, the displacement becomes steady; construction steps 20-55 were selected to analyze the deformation behavior.
As shown in Figure 9, under Method 1, the deformation during construction of the shaft support increased until the bottom of the shaft was permanently sealed, after which the deformation rate decreased until construction of the top heading of the cross passage began; then the deformation rate increased again. The shaft deformation stabilized at a value of $21.25 \mathrm{~mm}$ by Method 1. As shown in Figure 9, the top heading excavation of the horsehead in Method 2 had little effect on the deformation of the shaft after the temporary back cover of the shaft was completed. Then, following the excavation of the remaining soil and the bench of the horsehead, the supporting deformation increased but finally stabilized at a value of $18.20 \mathrm{~mm}$. The deformation rate produced by Method 1 was larger than that of Method 2. Thus, Method 2 reduced the final stabilized deformation of the shaft support by $3.05 \mathrm{~mm}$ (14.48\%) compared to that resulting from Method 1. Therefore, the temporary shaft support measures that were used in construction Method 2 helped to reduce the deformation of the shaft and would be expected to do well in controlling the deformation and velocity of the shaft support in actual practice.

Figure 10 shows the maximum principal stress distribution of the two construction methods in the horsehead section. The maximum principal stress resulting from both methods was located in the vertical shaft at the height of the top heading of the horsehead. The maximum principal stress produced by Method 2 was $1,469.39 \mathrm{kPa}$ less $(14.38 \%)$ than that produced by Method 1 .

Figure 11 shows the distribution of the maximum shear stress caused by the two construction methods in the horsehead section. For both methods, the position of the maximum shear stress was in the inside vertical shaft at the height of the top heading of the horsehead. The maximum shear stress produced by Method 2 was $838.36 \mathrm{kPa}$ less $(8.93 \%)$ than that produced by Method 1 .

4.5. Discussion. The "shaft followed by cross passage construction" method (Method 1) has been used for a long time and is a mature technology in China. However, the construction sequence in this method is complex and causes great 


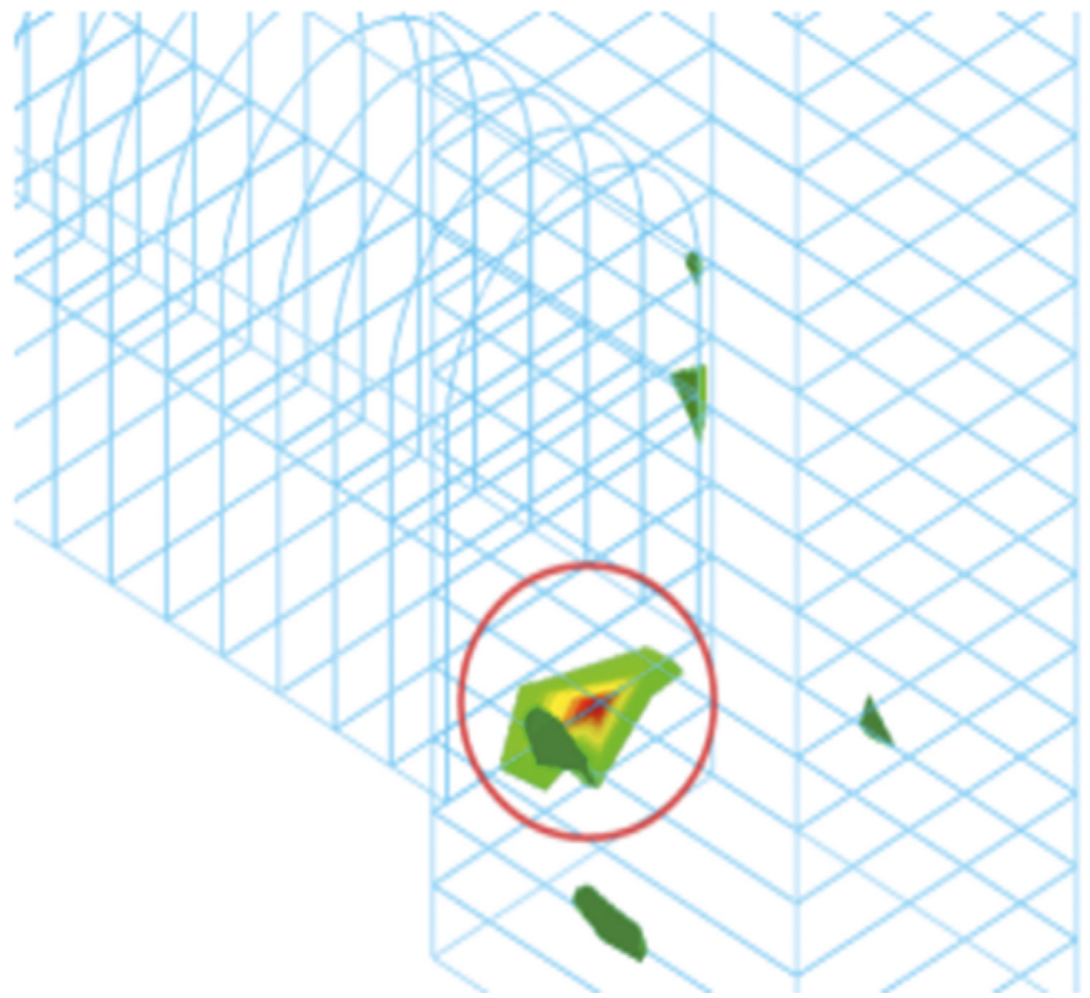

(a)

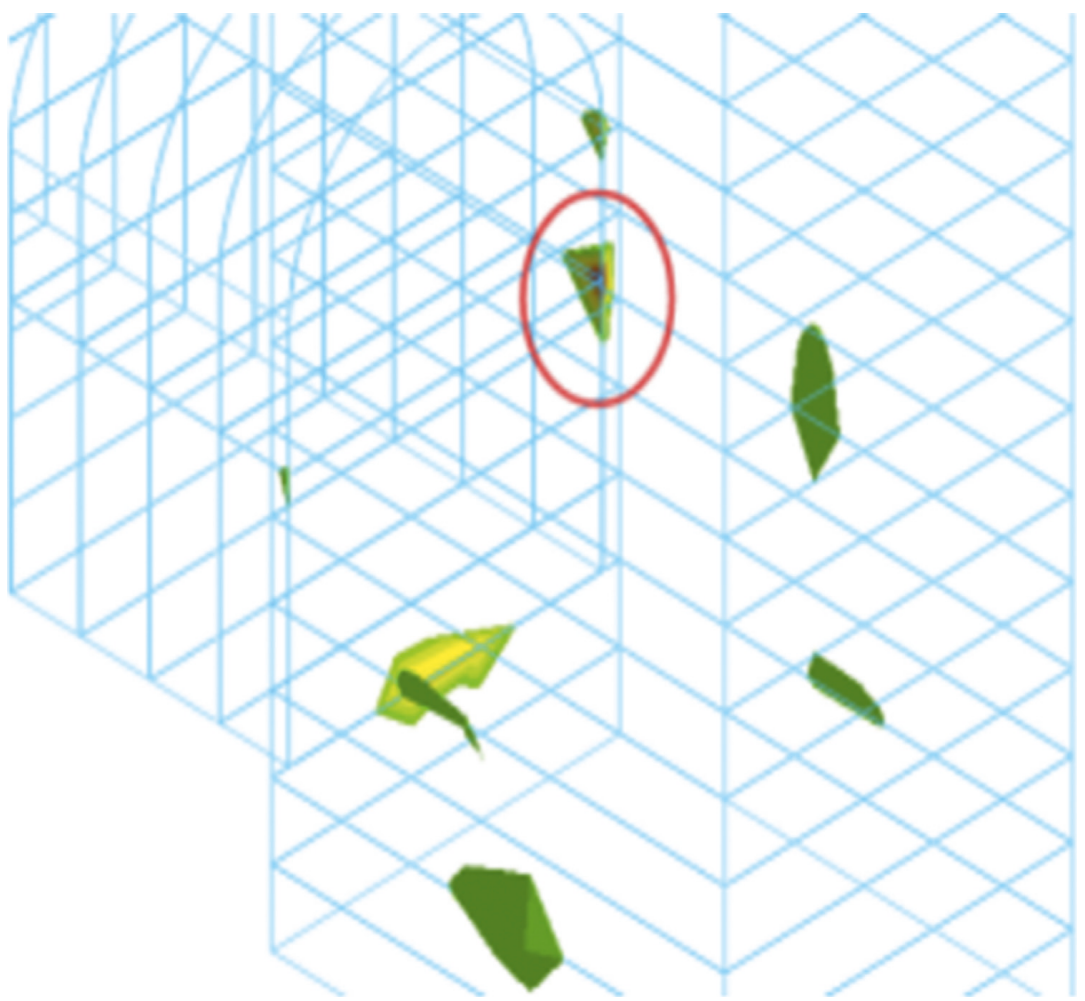

(b)

Figure 7: Distribution of maximum plastic deformation. (a) Method 1. (b) Method 2.

disturbance between each stage. In contrast, the relatively newer "cross passage parallel shaft construction" method (Method 2) depends only on a simple platform in the temporary back cover of the shaft before the top heading of the crossing passage can be constructed. Thus, in Method 2, construction is simpler and easier; furthermore, the time required for scaffolding erection 
TABLE 4: Maximum deformation of shaft (unit: $\mathrm{mm}$ ).

\begin{tabular}{|c|c|c|c|}
\hline Method & Directions & $\begin{array}{c}\text { Absolute } \\
\text { value }\end{array}$ & Position \\
\hline \multirow{3}{*}{ Method 1} & $\mathrm{X}$ & 17.48 & $\begin{array}{c}\text { The shaft wall near the invert } \\
\text { of the horsehead }\end{array}$ \\
\hline & $\mathrm{Y}$ & 25.46 & $\begin{array}{l}\text { The shaft wall near the two } \\
\text { haunches of the horsehead }\end{array}$ \\
\hline & $\mathrm{Z}$ & 38.15 & The bottom of the shaft \\
\hline \multirow{3}{*}{ Method 2} & $\mathrm{X}$ & 13.65 & $\begin{array}{c}\text { The shaft wall near the invert } \\
\text { of the horsehead }\end{array}$ \\
\hline & $\mathrm{Y}$ & 23.10 & $\begin{array}{l}\text { The shaft wall near the two } \\
\text { haunches of the horsehead }\end{array}$ \\
\hline & $\mathrm{Z}$ & 38.35 & The bottom of the shaft \\
\hline
\end{tabular}

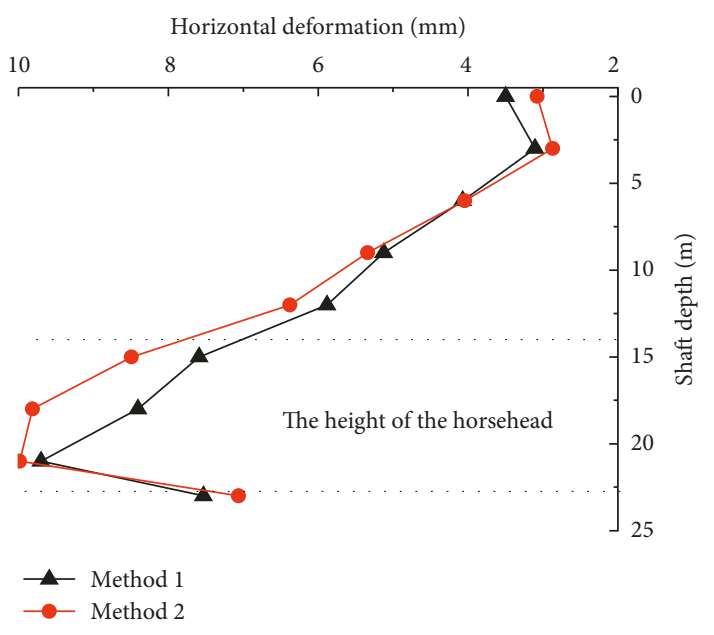

(a)

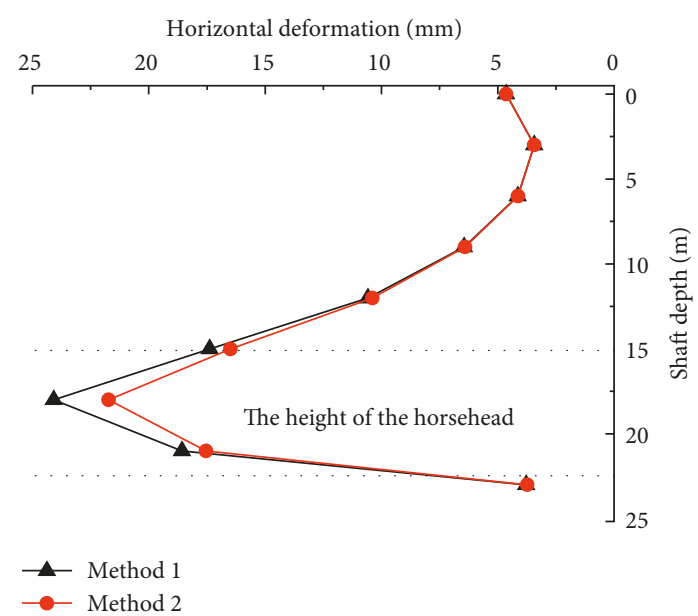

(b)

Figure 8: Deformation of shaft at different depths. (a) Deformations away from the horsehead. (b) Deformations parallel to the cross passage axis.

and removal is shorter, which reduces the workload and makes the entire construction sequence quicker. Importantly, in Method 2, construction workers do not need to stand on scaffolding during construction; therefore, the overall construction operations do not need to consider the risk of
TABLE 5: Maximum stress of shaft (unit: $\mathrm{kPa}$ ).

\begin{tabular}{lcccc}
\hline Method & \multicolumn{2}{c}{ Method 1 } & \multicolumn{2}{c}{ Method 2 } \\
Stress & $\begin{array}{c}\text { Maximum } \\
\text { principal } \\
\text { stress }\end{array}$ & $\begin{array}{c}\text { Ultimate } \\
\text { shear } \\
\text { stress }\end{array}$ & $\begin{array}{c}\text { Maximum } \\
\text { principal } \\
\text { stress }\end{array}$ & $\begin{array}{c}\text { Ultimate } \\
\text { shear } \\
\text { stress }\end{array}$ \\
$\begin{array}{l}\text { Absolute } \\
\text { value }\end{array}$ & $10,216.00$ & $10,618.21$ & $8,746.61$ & $8,539.54$ \\
Position & The shaft wall near the arch of the horsehead
\end{tabular}

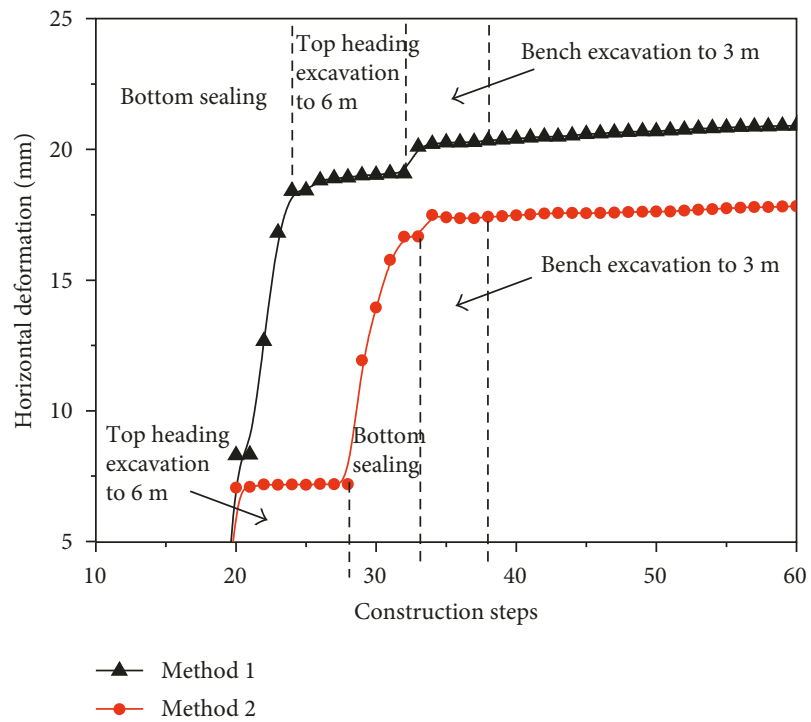

FIgURE 9: Horizontal deformation of shaft at different construction steps.

working at height. Thus, Method 2 also is good at avoiding construction safety hazards and ensuring the safety of construction workers.

In addition, the comparative analysis of the numerical simulation results for the two construction methods showed that Method 2 can control the deformation and force of the original shaft structures more effectively than Method 1 . Considering the actual demands of the subway construction, especially the need to shorten the construction period, it was concluded that the construction of the cross passage from the subway shaft at the Yue Deng Pavilion-San Dian Village Station tunnel section should be carried out using Method 2, namely, "cross passage parallel shaft construction" method, and that support of the horsehead should be strengthened during construction to ensure that the position remained stable.

4.6. Model Size and Boundary Condition Effects. A large number of numerical simulation results show that when the size of the numerical model was relatively small, the size of the boundary has serious influence on the results; when the size of the boundary exceeded a specific value, the influence of the boundary effect can be negligible. In order to verify the validity of the selected boundaries of the numerical model in Section 3.2, models with different side boundaries (1.0, 2.0, $3.0,4.0,5.0,6.0,7.0$, and 8.0 times the width of the shaft) and 


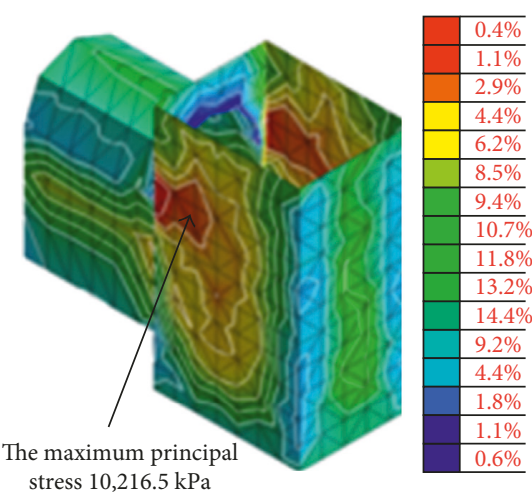

(a)

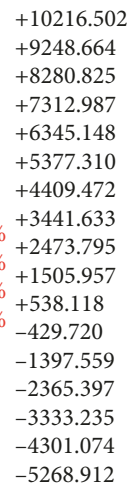

$-5268.912$

$z$
$\lambda_{x}^{y}$
$y_{x}$

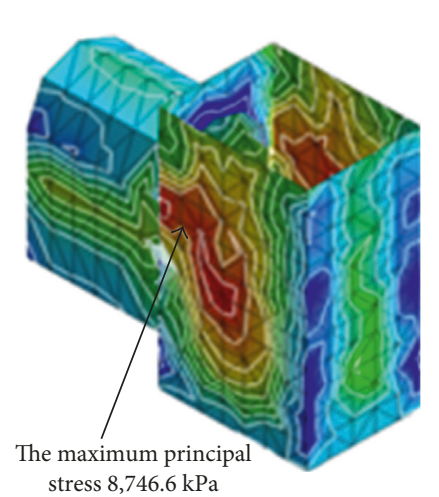

(b)

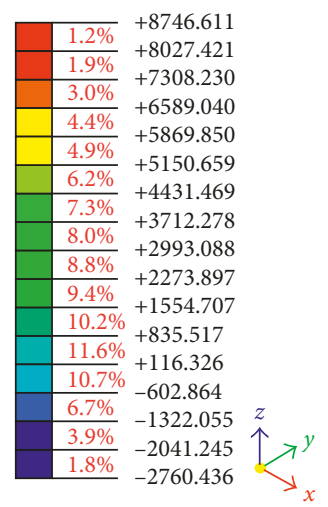

FIgURE 10: Maximum principal stress distribution in the horsehead. (a) Method 1. (b) Method 2.

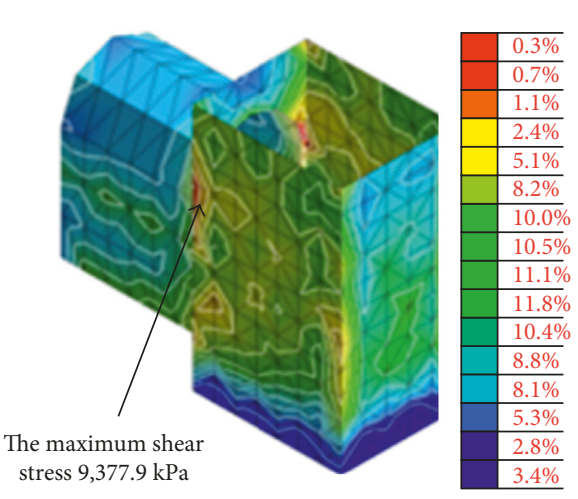

(a)

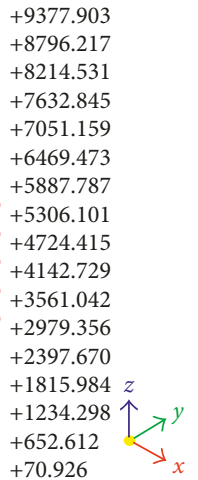
$+70.926$

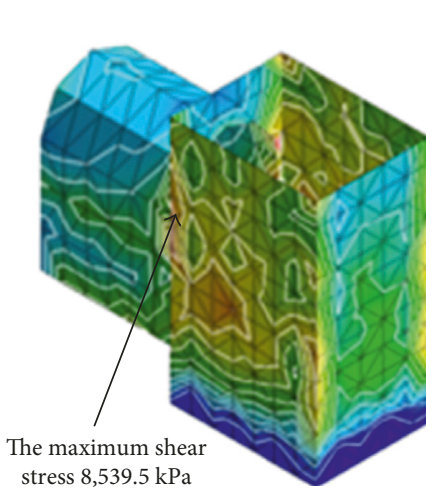

(b)

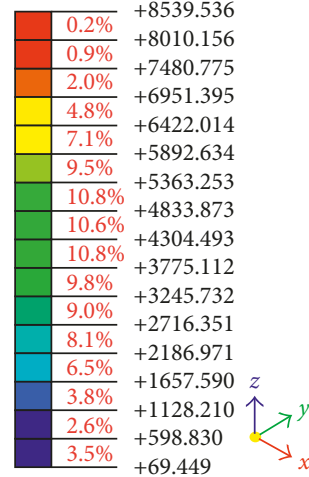

$+69.449$

FIgURE 11: Maximum shear stress distribution in the horsehead. (a) Method 1. (b) Method 2.

different bottom boundaries $(1.0,1.5,2.5,3.5,4.5,5.5,6.5$, and 7.5 times the height of the cross passage) were further established to analyze the influence of the boundary effect on the calculation results.

Figure 12 shows the vertical deformation of the top position and the lateral deformation of the central position in the horsehead section with different boundaries at the end of construction. Figure 12(a) demonstrates the change of the deformation of the selected positions with different side boundaries that were counted by different times the width of the shaft. Figure 12(b) demonstrates the change of the deformation of the selected points with different bottom boundaries that were counted by different times the height of the cross passage.

As shown in Figure 12(a), the distance between the side of the shaft and the model boundary had greater influence on the lateral deformation of the central position in the horsehead section. When the distance was more than the 4 times the width of the shaft, the lateral deformation was approximately no longer change. Comparing with the stable lateral deformation, the lateral deformation resulting from 3 times the width of the shaft was about less than $2.87 \%$. As shown in Figure 12(b), the distance between the bottom of the cross passage and the boundary had greater influence on the vertical deformation of the top position in the horsehead section. When the distance was more than the 3.5 times the height of the cross passage, the vertical deformation was approximately no longer change. Comparing with the stable vertical deformation, the vertical deformation resulting from 2.5 times the height of the cross passage was about less than $2.5 \%$. The errors resulting from the side boundary ( 3 times the width of the shaft) and the bottom boundary (2.5 times the height of the cross passage) in Section 3.2 were both less than $5 \%$. Therefore, the size of selected boundary was reliable to optimally analyze different methods.

\section{Shaft Crossing Passage Construction Points and Site Monitoring}

5.1. Construction Technology Based on Numerical Simulation Analysis. Based on the results of numerical simulation analysis, the construction of the cross passage from the subway shaft on the Yue Deng Pavilion-San Dian Village Station tunnel section was actually carried out using the "cross passage parallel shaft construction" method (Method 2). Considering the actual situation of the site, the construction 


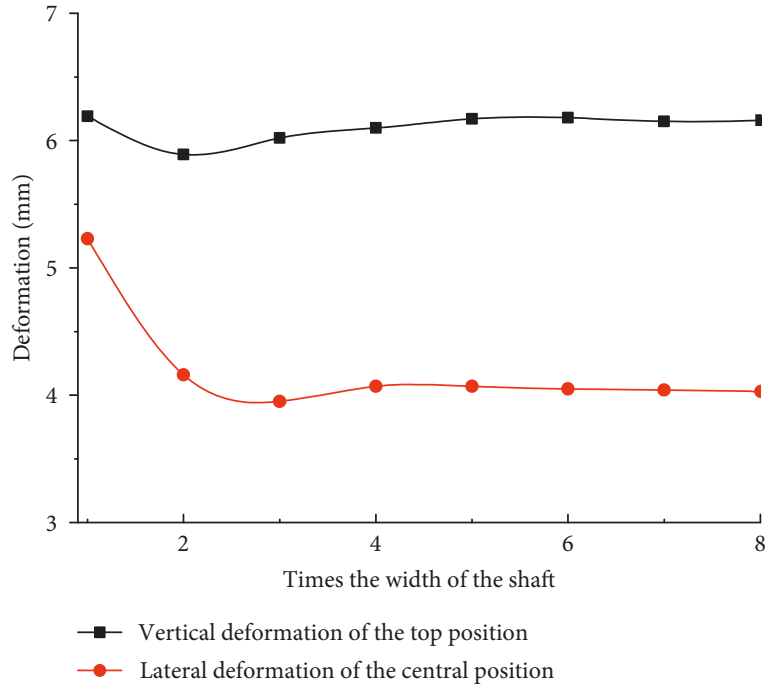

(a)

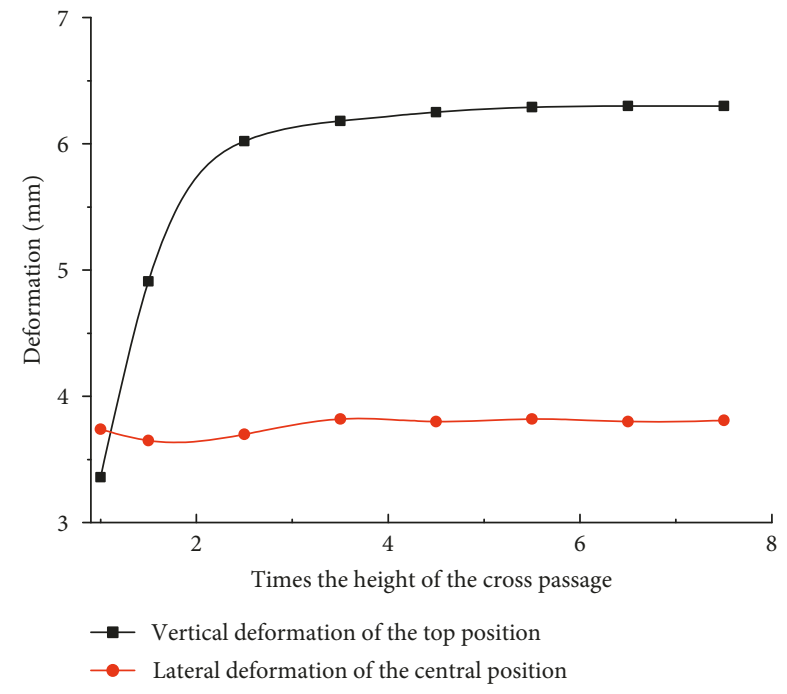

(b)

Figure 12: Deformations of the selected points in the horsehead section with different boundaries. (a) Deformations with different side boundaries. (b) Deformations with different bottom boundaries.

sequence and construction control points of the shaft and cross passage were as follows.

(1) First, the designed shaft position was ensured. Then excavation of the locking region of shaft was begun, and shaft support for the locking part was set up. To prevent flooding by surface water, the height of the shaft lock was $0.3 \mathrm{~m}$ higher than that of the ground surface. To expand the import force area, the concrete pour around the well was extended outward by $0.2 \mathrm{~m}$. Finally, a safety barrier and door were constructed around the wellhead at a height exceeding $1.2 \mathrm{~m}$.

(2) The excavation of the standard section of the shaft was accomplished using the top-down excavation method in which the footage was $0.5 \mathrm{~m}$. The construction was carried from top to bottom, and the supporting structures were installed immediately after the excavation. In view of the complexity of the loess stratum, full-section excavation of the shaft was avoided by using blocking and slicing excavation. The excavation sequence is shown in Figure 13.

(3) When the shaft excavation was approximately $1.5 \mathrm{~m}$ from the groundwater level elevation, excavation was continued only after exploring the precipitation effect on the groundwater level. According to the groundwater situation, appropriate measures were taken to ensure that work proceeded without water ingress to ensure the stability of the bottom of the shaft during construction.

(4) When each footage was constructed in the shaft blocking and slicing excavation, it was inspected and $40 \mathrm{~mm}$ of sprayed concrete was placed. The $\Phi 6.5$ @ $150 \mathrm{~mm} \times 150 \mathrm{~mm}$ steel was welded into a doublereinforced grid. Finally, the steel frame was constructed and sprayed with C25 concrete to a thickness of $400 \mathrm{~mm}$.

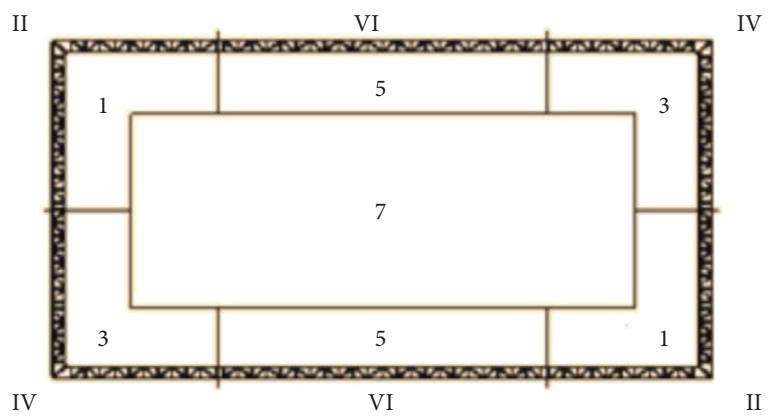

FIGURE 13: Shaft excavation and supporting sequence.

(5) In the consolidation grouting construction and the back-filling construction, the grouting steel pipe with $\Phi 42 \times 3.5$ and $L=3 \mathrm{~m}$ was set. Each grid frame was set once, and the ring space was $0.4 \mathrm{~m}$. The $(1: 1)$ cement-water-glass double slurry for consolidation and injection of concrete support wall were sprayed immediately after the grouting construction, in which construction parameters were determined according to the field test.

(6) When the shaft was excavated to the horsehead position, a steel frame was strengthened on the top heading of horsehead, and the shaft was continuously excavated to the bottom of the top heading of the horsehead. The C25 spray concrete with a thickness of $300 \mathrm{~mm}$ was set to fill the bottom of the shaft, and the construction direction transferred to the cross passage.

(7) The horsehead construction was the key to the intersection construction between the shaft and the cross passage. According to the numerical simulation analysis, the stress state of horsehead structure 


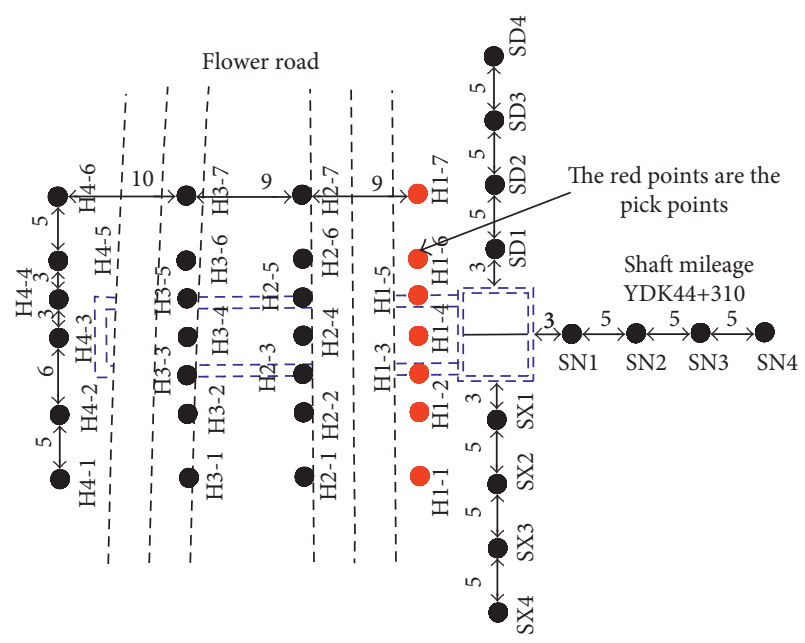

Figure 14: Layout of deformation measuring points at ground surface.

was complicated, so the construction process of this component became the focus of attention. To ensure safety, the support replacement used the I-20 steel at the top heading excavation of the cross passage before breaking over construction of the horsehead; this was then removed after completing the construction of the hole.

(8) The leading conduit of the dome of the cross passage with $\Phi 42 \times 3.5$, and $L=4 \mathrm{~m}$, was constructed to advance the grouting and firm the stratum of the cross passage. After the leading conduit construction was completed, the horsehead excavation began. The three I-20 steel frames were set in parallel then sprayed with concrete to a thickness of $500 \mathrm{~mm}$.

(9) The ring-like drift heading method with preformed core soil was carried out in the construction of the cross passage. The remaining part of the shaft was constructed after the cross passage construction reached $4 \mathrm{~m}$. The shaft was excavated to the design depth for permanent back cover construction. The I-20a I-beams spaced on $0.5 \mathrm{~m}$ centers were placed, and the net was sprayed with C25 concrete to a thickness of $350 \mathrm{~mm}$ to complete the back cover construction. After the completion of the back cover, the bench excavation of the cross passage was carried out. Depending on setting the temporary ladder and other ancillary construction facilities, the intersection construction was completed.

5.2. Field Monitoring Data. To ensure the safety of the shaft and cross passage construction, the surface settlement and the shaft deformation caused by the "cross passage parallel shaft construction" method were monitored during construction. The shaft surface monitoring points of the Yue Deng Pavilion-San Dian Village Station tunnel section are shown in Figure 14. Once the deformations at the monitoring points were stable, the monitoring data were compared with the numerical simulation results.

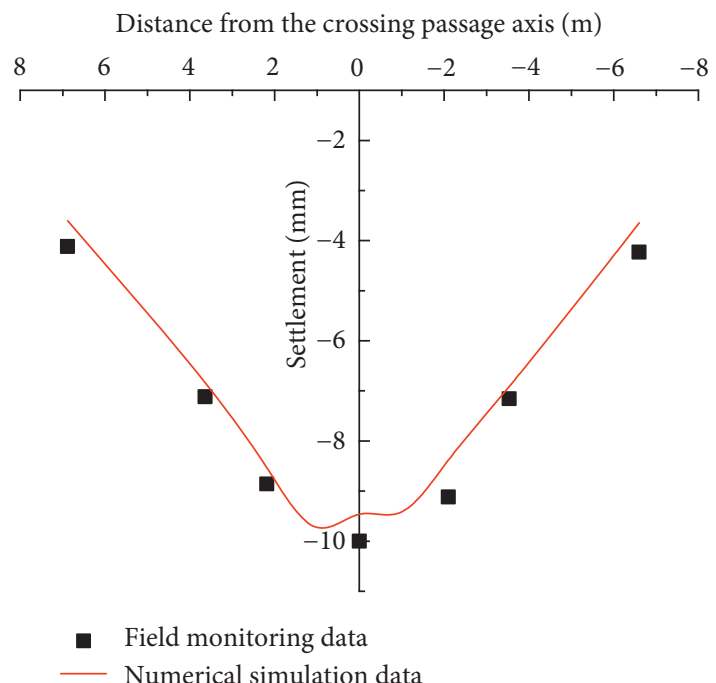

(a)

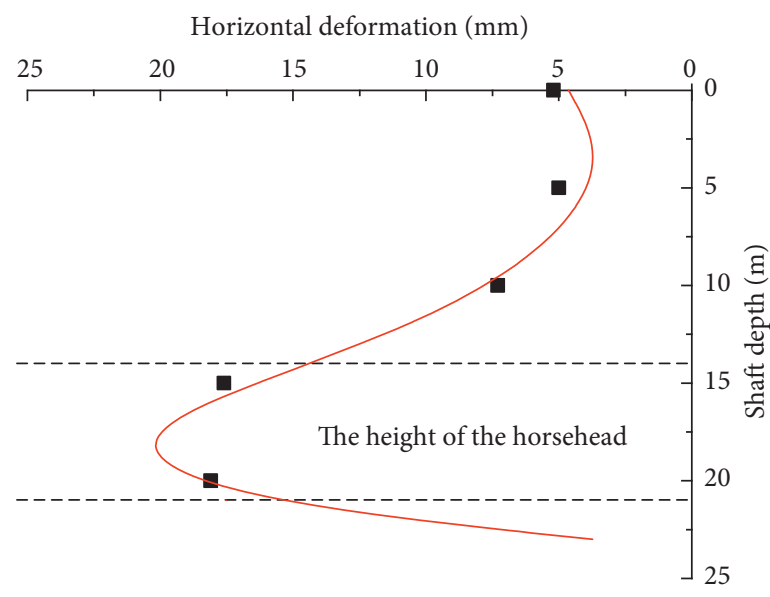

- Field monitoring data

Numerical simulation data

(b)

FIgURE 15: Comparisons of the field monitoring data and numerical simulation results. (a) Surface settlements. (b) Deformation of the shaft support.

Figure 15 compares selected monitoring data and simulation results. In Figure 15(a), the surface subsidence monitoring and simulation results of the $\mathrm{H} 1$ series (the red line) are compared. As shown, the observed construction monitoring data were very similar to those in the simulation analysis, although the numerical simulation results were smaller than the observed data. The difference between the simulation results and the actual results was mainly caused by the creep effect of the soil in the actual project. Due to the influence of shaft and cross passage construction, the maximum observed settlement was approximately $10 \mathrm{~mm}$, which was significantly less than the allowable control value of $30 \mathrm{~mm}$.

Figure 15(b) shows deformation monitoring data and simulation results at different depths of the shaft support in the direction parallel to the cross passage axis. The 
monitoring section was divided into five segments, each with a depth of $5 \mathrm{~m}$. As shown, the observed horizontal deformation and simulated value of the vertical shaft structure were quite different from the horizontal deformation of the shaft support in the height range of the horsehead. In the actual construction, the horsehead support was strengthened, making the observed horizontal deformation of the shaft support smaller than that predicted by the simulation. The simulated and observed surface deformation and shaft structure deformation caused by the "cross passage parallel shaft construction" method were within $15 \mathrm{~mm}$, meeting the construction requirements. Thus, the use of the "cross passage parallel shaft construction" method was technically and economically viable.

\section{Conclusions}

The main line tunnel of Subway Line 5 in Xi'an, China, was placed in the loess stratum and was constructed through the cross passage from the subway shaft at the Yue Deng Pavilion-San Dian Village Station tunnel section. This research focused on the construction stability in the loess material. The ground surface deformation, surrounding rock mass plastic zone, and the deformation and state of stress of the original shaft support structure were analyzed as a result of two construction methods: "shaft followed by cross passage construction" and "cross passage parallel shaft construction." Combining simulated responses and field monitoring data, the following conclusions can be drawn.

The ground settlement and the plastic deformation of the surrounding rock caused by both construction methods are basically the same in the loess formation, but the maximum plastic deformation position of the surrounding rock is different. Therefore, different construction methods should strengthen different locations in a construction project to prevent excessive deformation of the surrounding rock.

Compared with the "shaft followed by cross passage construction" method, the "cross passage parallel shaft construction" method has more advantages in controlling the displacement and stress of the original shaft structure, especially for the shaft structure in the cross passage excavation direction. In this study, the maximum deformation caused by the latter construction method was $14.48 \%$ (3.05 mm) less than that caused by the former, and the maximum stress and the maximum shear stress were $14.38 \%$ and $19.57 \%$ less, respectively, when construction was complete.

Under both construction methods, the local stress concentration of the shaft wall will appear near the horsehead, so this location is the key position for construction reinforcement. However, in terms of stress values, the maximum principal stress and the maximum shear stress in the "cross passage parallel shaft construction" method are $14.38 \%$ and $8.93 \%$ less, respectively, than comparable stresses caused by the "shaft followed by cross passage construction" method. The temporary back-filling measures of the shaft in the "cross passage parallel shaft construction" method can help to reduce the deformation of the shaft support and achieve better results in controlling the deformation value and velocity of the shaft support. Therefore, the "cross passage parallel shaft construction" method makes the horsehead support safer than does the other construction method.

The field monitoring data show that the deformation of the ground surface and shaft structures produced by the "cross passage parallel shaft construction" method in the loess stratum was less than $15 \mathrm{~mm}$, which satisfied the safety requirements and was close to the numerical simulation results. Therefore, the "cross passage parallel shaft construction" method is safe and feasible for use in a loess stratum, and the results of this research can be reference for similar construction projects.

\section{Conflicts of Interest}

The authors declare no conflicts of interest.

\section{Acknowledgments}

This paper is supported by the National Natural Science Foundation of China (Nos. 51578447 and 51404184) and the Natural Science Basic Research Program of Shanxi Province (No. 2016JQ4009).

\section{References}

[1] J. X. Lai, J. Qiu, H. Fan et al., "Structural safety assessment of existing multiarch tunnel: a case study," Advances in Materials Science and Engineering, vol. 2017, Article ID 1697041, 11 pages, 2017.

[2] Z. P. Song, T. T. Yang, and A. N. Jiang, "Elastic-plastic numerical analysis of tunnel stability based on the closest point projection method considering the effect of water pressure," Mathematical Problems in Engineering, vol. 2016, Article ID 2569345, 12 pages, 2016.

[3] J. X. Lai, B. F. Hao, Z. L. Bang, and L. Tong, "Analysis of seismic response of shallow large section multi-arch tunnel," Procedia Engineering, vol. 15, pp. 5473-5477, 2011.

[4] Y. Y. Li, X. G. Jin, Z. T. Lv, J. H. Dong, and J. C. Guo, "Deformation and mechanical characteristics of tunnel lining in tunnel intersection between subway station tunnel and construction tunnel," Tunnelling and Underground Space Technology, vol. 56, pp. 22-23, 2016.

[5] Y. D. Huang, X. L. Gong, Y. I. Peng, and C. N. Kim, "Effects of the solid curtains on natural ventilation performance in a subway tunnel," Tunnelling and Underground Space Technology, vol. 38, pp. 526-533, 2013.

[6] M. Afifipour, M. Sharifzadeh, K. Shahriar, and H. Jamshidi, "Interaction of twin tunnels and shallow foundation at $\mathrm{Z}$ and underpass, Shiraz Metro, Iran," Tunnelling and Underground Space Technology, vol. 26, no. 2, pp. 356-363, 2011.

[7] N. A. Do, D. Dias, P. Oreste, and I. Djeran-Maigre, "Threedimensional numerical simulation of a mechanized twin tunnels in soft ground," Tunnelling and Underground Space Technology, vol. 42, pp. 40-51, 2014.

[8] S. C. Li, H. L. Liu, L. P. Li, Q. Q. Zhang, K. Wang, and K. Wang, "Large scale three-dimensional seepage analysis model test and numerical simulation research on undersea tunnel," Applied Ocean Research, vol. 59, pp. 510-520, 2016.

[9] H. Gercek, "Stability considerations for underground excavation intersections," Mining Science and Technology, vol. 4, no. 1, pp. 49-57, 1986. 
[10] L. L. Guan, S. H. Baldauf, and W.-P. N. Chen, "Three dimensional simulation of progressive tunneling process for lining design of intersecting tunnels in soft rock," in Computing in Civil Engineering, ASCE, Reston, VA, USA, 1994.

[11] G. Gaspari, O. Zanoli, and M. Pescara, "Three-dimensional modelling of the tunnel intersections in weak rock mass on the Kadikoy-Kartal metro line of Istanbul," in Proceedings of the ISRM International Symposium-EUROCK 2010, International Society for Rock Mechanics, Puerto de la Cruz, Spain, June 2010.

[12] A. G. Bloodworth and G. T. Houlsby, "Three dimensional analysis of building settlement caused by shaft construction," in Proceedings of the International Symposium on Geotechnical Aspects of Underground Construction in Soft Ground, pp. 607612, Tokyo, Japan, 2000.

[13] W. H. Tan, H. B. Sun, and R. J. Li, "Stability analysis on rectangular transition section tunneling in Beiwan horsehead region of no. 7 subway," Advanced Materials Research, vol. 446-449, pp. 2224-2228, 2012.

[14] F. Hsiao, C. L. Wang, and J. Chern, "Numerical simulation of rock deformation for support design in tunnel intersection area," Tunnelling and Underground Space Technology, vol. 24, no. 1, pp. 14-21, 2009.

[15] F. E. Wang and F. L. Zhang, "Study on the opening technology of horsehead between subway shaft and cross aisle," Anhui Architecture, vol. 16, no. 3, pp. 54-55, 2009, in Chinese.

[16] C. J. He, Z. Y. Jiang, Z. J. Cui, and C. Y. Liu, "Ingate excavation technology of urban underground engineering construction," Municipal Engineering Technology, vol. 27, no. 3, pp. 17-21, 2012, in Chinese.

[17] M. L. Bai and X. M. Ji, "Numerical simulation analysis of large-span tunnel construction through cross aisle from subway small shaft," Chinese Journal of Underground Space and Engineering, vol. 11, no. 2, pp. 469-476, 2015, in Chinese.

[18] Q. Q. Jiang, X. Y. Huang, K. Zhou, and Z. F. Chen, "Construction technology and monitoring analysis of subway tunnel in gate under complex condition," Chinese Journal of Rock Mechanics and Engineering, vol. 29, no. 1, pp. 2858-2865, 2010, in Chinese.

[19] J. L. Rong, D. L. Jun, Y. Rui, Z. Wen, and J. S. Sheng, "Characteristics of structural loess strength and preliminary framework for joint strength formula," Water Science and Engineering, vol. 7, no. 3, pp. 319-330, 2014.

[20] C. L. Chen, S. J. Shao, A. Z. Luo, and J. Fang, "Study on the static spatially mobilized plane and its strength criterion adaptability," Chinese Journal of Underground Space and Engineering, vol. 11, no. 5, pp. 1185-1192, 2015, in Chinese.

[21] B. P. Wen and Y. J. Yan, "Influence of structure on shear characteristics of the unsaturated loess in Lanzhou, China," Engineering Geology, vol. 168, pp. 46-58, 2014.

[22] H. Chakeri and B. Unver, "A new equation for estimating the maximum surface settlement above tunnels excavated in soft ground," Environmental Earth Sciences, vol. 71, no. 7, pp. 3195-3210, 2014.

[23] R. P. Chen, J. Zhu, W. Liu, and X. W. Tang, "Ground movement induced by parallel EPB tunnels in silty soils," Tunneling and Underground Space Technology, vol. 26, no. 1, pp. 163-171, 2011.

[24] D. Aurich, "The influence of the stress state on the plastic zone size," Engineering Fracture Mechanics, vol. 7, no. 4, pp. 761$765,1975$.

[25] Z. F. Tian, Z. M. Su, and N. H. Jiang, "The nonlinear analysis of sensitivity of the plastic zone of surrounding rock in underground caverns," Advanced Materials Research, vol. 926930, pp. 687-692, 2014. 


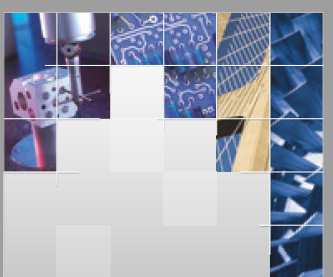

\section{Enfincering}
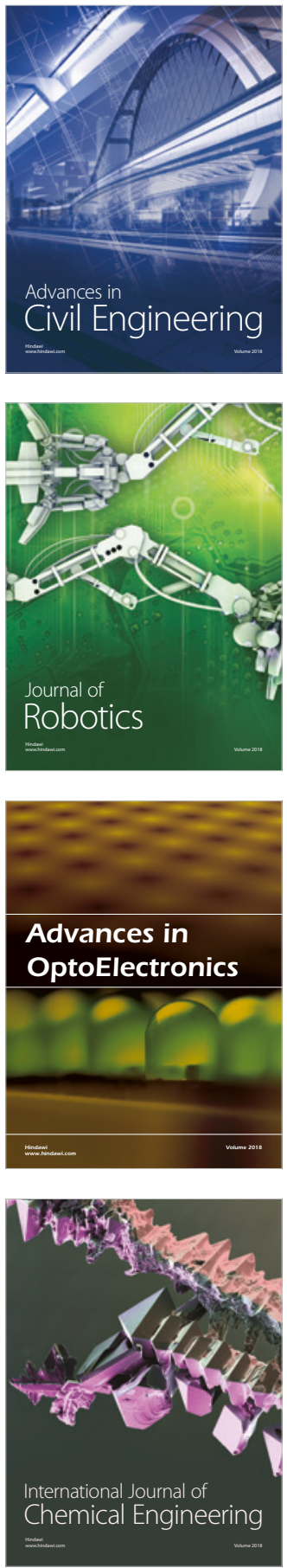

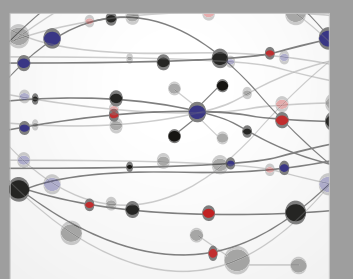

\section{Rotating \\ Machinery}

The Scientific World Journal

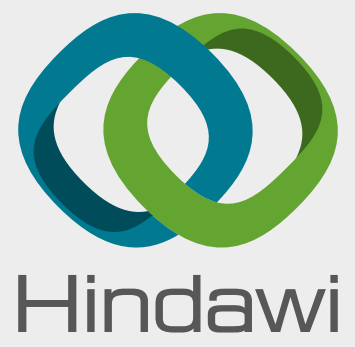

Submit your manuscripts at

www.hindawi.com
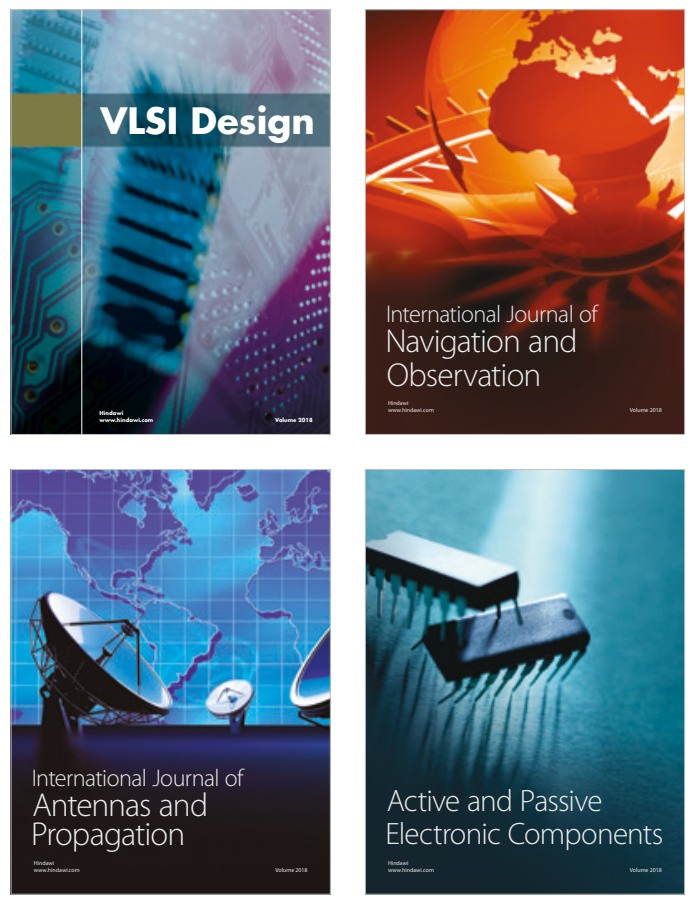
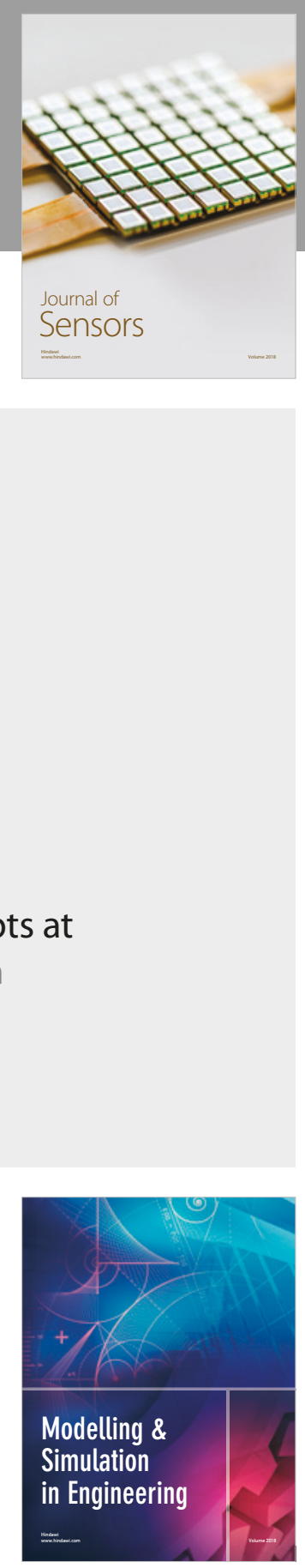

\section{Advances \\ Multimedia}
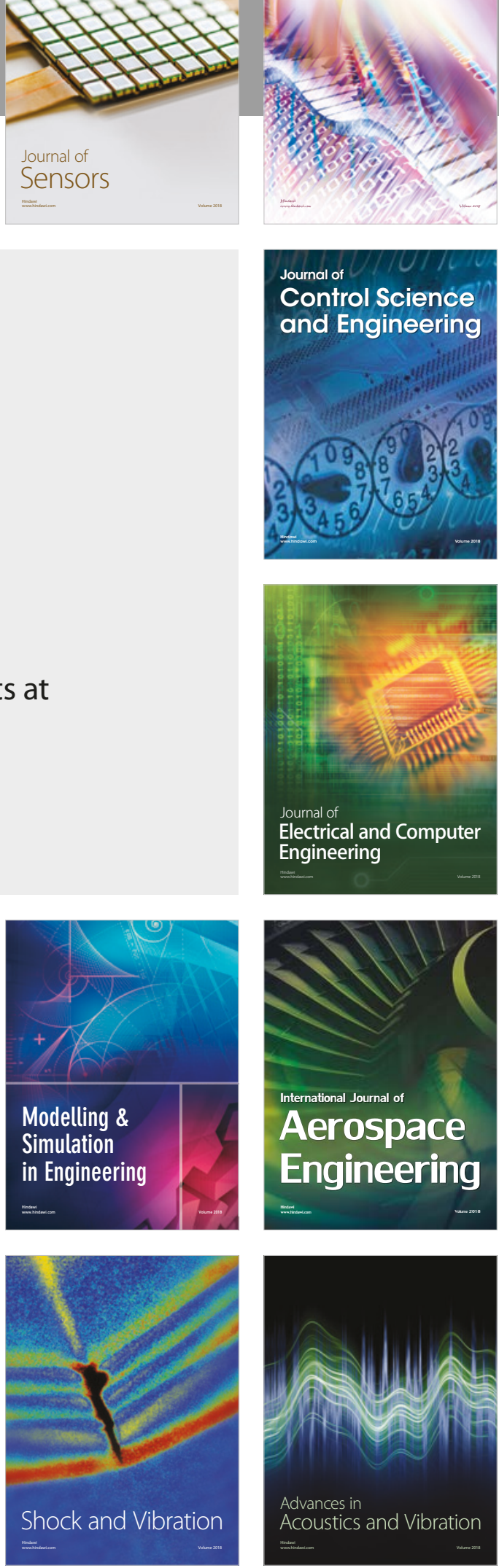